\title{
Trabalho docente, saúde e gênero: implicações da conjuntura político-econômica na educação superior
}

\author{
Thiele Duarte Reis ${ }^{1}$ \\ https://orcid.org/0000-0003-4514-3577
}

\author{
Claudia March ${ }^{2}$ \\ https://orcid.org/0000-0001-5651-9512
}

${ }^{1}$ Universidade Federal Fluminense, Instituto de Saúde Coletiva, Rio de Janeiro, RJ, Brasil

${ }^{2}$ Universidade Federal Fluminense, Instituto de Saúde Coletiva, Niterói, RJ, Brasil

\begin{abstract}
Trabalho docente, saúde e gênero: Implicações da conjuntura político-econômica na educação superior
\end{abstract}

Resumo: O presente artigo é derivado da dissertação de mestrado intitulada "Trabalho docente, Saúde e Gênero: Um Estudo em uma Unidade Acadêmica de uma Universidade Federal". O objeto de estudo trata-se de uma das categorias encontradas nos resultados da pesquisa sobre as relações entre trabalho, saúde e gênero segundo a perspectiva das docentes de uma unidade de ensino da área de saúde de uma universidade pública federal do Rio de Janeiro. Na pesquisa supracitada foram entrevistadas 13 professoras universitárias e a abordagem marxista e marxiana foi tida como referencial teórico, além disso a técnica de análise dos dados foi a hermenêutica dialética. As implicações da conjuntura política e econômica para a educação superior e seus efeitos para o trabalho docente foi recorrente no discurso das docentes e eleito para este artigo pela relevância no atual contexto político de profundas modificações no ensino superior público e no trabalho docente.

Palavras-chave: Trabalho docente. Gênero. Saúde do Trabalhador. Conjuntura político e econômica.

\section{Teaching work, health and gender: implications of the political-economic situation in higher education}

Abstract: This article is derived from the master's thesis entitled "Teaching work, Health and Gender: A Study in an Academic Unit of a Federal University". The object of study is one of the categories found in the results of the research on the relations between work, health and gender according to the perspective of the teachers of a teaching unit in the health area of a federal public university in Rio de Janeiro. In the aforementioned research, 13 university professors were interviewed and the Marxist and Marxian approach was taken as a theoretical framework, in addition the data analysis technique was dialectical hermeneutics. The implications of the political and economic situation for higher education and its effects on teaching work was recurrent in the speech of teachers and elected for this article due to its relevance in the current political context of profound changes in public higher education and in teaching work.

Keywords: Teaching work. Gender. Worker's health. Political and economic situation.

Recebido em 18.09.2020. Aprovado em 15.12.2020. Revisado em 29.01.2021.

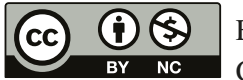

Este é um artigo publicado em acesso aberto (Open Access) sob a licença Creative Commons Attribution NonCommercial, que permite uso, distribuição e reprodução em qualquer meio, sem restrições desde que sem fins comerciais e que o trabalho original seja corretamente citado. 


\section{Introdução}

A respeito do trabalho na vida das mulheres, os textos marxistas já apontavam a condição de desvantagem das mulheres no mercado de trabalho, decorrente de serem responsáveis prioritárias pelo cuidado do lar, localizando a sua situação de opressão econômica no trabalho doméstico, o que as afastava da produção social e da participação das mulheres na luta política por melhores condições salariais e de trabalho.

As atividades demandadas às mulheres pelo mercado de trabalho se expressam em qualidades consideradas próprias e inerentes à natureza feminina (destreza, minúcia, paciência, cuidados com o outro, entre outras). Essas características são desqualificadas, simbólica e economicamente, a partir da concepção de que expressam apenas qualidades femininas, sendo assim consideradas inerentes, naturais, apreendidas pelas mulheres desde a infância em seu processo de socialização (KERGOAT, 2009).

No âmbito da Educação, em profissões como a docência, há uma relação entre as características supostamente femininas e o incentivo à profissionalização de mulheres. Assim, a divisão sexual do trabalho é pautada por uma diferenciação biológica entre homens e mulheres, que se tornam justificativas ideológicas para destinar homens a determinadas atividades e mulheres a outras, conferindo diferente valor social; isto é, menor prestígio e remuneração.

O trabalho docente de mulheres e homens no nível superior se insere no complexo de determinações que está colocado, com destaque para as mudanças que se intensificam a partir da década de 1990, incluindo a contrarreforma do Estado e suas repercussões na educação pública. As professoras e os professores estão submetidos a altas exigências de produção técnico-científica, ensino, pesquisa e extensão, além de diversas atividades administrativas.

Silva Júnior (2017) em seu livro "The new Brazilian university: A busca por resultados comercializáveis: Para quem?" se debruça sobre o novo papel das universidades estatais brasileiras, que se estruturam, nas últimas décadas, pelo chamado regime do capitalismo acadêmico. Guiado pela "economia mundial, cujo conhecimento produzido busca a comercialização de serviços, processos e produtos de alta tecnologia", tem "uma concepção que vem influenciando a maioria das universidades no mundo todo, num contexto de divisão acadêmica do trabalho" (SILVA JÚNIOR, 2017, p. 123). Como pontua o autor, no Brasil essas mudanças são recentes e atravessadas pelas especificidades histórico-culturais brasileiras (SILVA JÚNIOR, 2017).

No entender de Silva Júnior e Fargoni (2020), a conjuntura mais recente adensa-se a partir do aprofundamento das políticas neoliberais em um pacto com os fascistas. Os autores apresentam as categorias do bolsonarismo, dentre as quais destacamos o anti-intelectualismo, o autoritarismo e a prepotência, a aversão à pluralidade $\mathrm{e}$ a intolerância e preconceito, incluindo o machismo.

Para os autores, o totalitarismo e o protofascismo, por exemplo, aparecem constantemente no confronto com a comunidade científica, principalmente as universidades e institutos federais (SILVA JÚNIOR; FARGONI, 2020).

Citando Mbembe (2016), os autores supracitados caracterizam a conjuntura atual e seus impactos para as instituições federais de ensino, que combina políticas de austeridade, com os cortes no financiamento, como o apelo à exceção, à emergência e a uma noção ficcional de inimigo.

Na conjuntura mais recente, as mudanças no trabalho docente que vêm se moldando nas universidades públicas e a política pautada pelo autoritarismo, anti-intelectualismo e intolerância, apontam para a relevância da temática de nossa pesquisa.

Este artigo é parte de uma pesquisa cujo objetivo foi analisar as relações entre trabalho, saúde e gênero sob a perspectiva das docentes de uma unidade de ensino da área de saúde de uma universidade pública federal do Rio de Janeiro. No presente artigo, o recorte feito se refere às implicações da conjuntura político-econômica e seus efeitos para a saúde a partir das falas das docentes entrevistadas.

Para tanto, assumimos, no presente trabalho, a teoria social Marxista que analisa a dinâmica e estrutura da sociedade burguesa. Na análise da relação entre saúde e trabalho das docentes universitárias, por consequência, nossa interlocução se dá com a sociologia do trabalho, com autoras marxistas que assumem a interseccionalidade nas análises da relação entre trabalho e saúde das mulheres, com a produção da Medicina Social Latino-americana e com as pesquisas do campo da educação sobre o trabalho docente no ensino superior. 
Este estudo se caracteriza como descritivo, de abordagem qualitativa e de caráter exploratório, submetido ao Comitê de Ética em Pesquisa da Faculdade de Medicina da Universidade Federal Fluminense e aprovado pelo parecer de $\mathrm{n}^{\circ}(3.383 .563)$.

Os sujeitos dessa pesquisa, selecionados para participar do estudo, tiveram suas identidades totalmente resguardadas, segundo os preceitos da Resolução 196 de 1996 do Conselho Nacional de Ética e Pesquisa (CONEP), de acordo com o Código de Nuremberg, Declaração de Helsinque e a mais atual Resolução 466 de 2012 do Conselho Nacional de Saúde (CNS), sendo consideradas e respeitadas as normas de Pesquisa Envolvendo Seres humanos.

Foram realizadas entrevistas semiestruturadas com professoras universitárias de uma unidade acadêmica do curso da saúde sobre trabalho docente em sua relação com a saúde e o gênero. Antes de iniciar a coleta de dados, foi solicitado o consentimento da Universidade para a realização das entrevistas na unidade de ensino, assim como para análise e aprovação do projeto pelo Comitê de Ética em pesquisa. Uma vez finalizado esse processo, foram realizadas visitas aos departamentos, para contatar os chefes de departamentos e após foram contatadas as possíveis participantes da pesquisa para esclarecê-las sobre os objetivos da pesquisa e suas contribuições para o trabalho.

Foram esclarecidas as dúvidas e questões a respeito do Termo de Consentimento Livre Esclarecido (TCLE), sobre o instrumento de coleta de dados, acerca da divulgação dos dados e da garantia do anonimato, além de informações pertinentes à ética em pesquisas com seres humanos. O TCLE, no qual citamos os princípios éticos que nortearam a pesquisa, foi lido, com o intuito de expor o porquê de sua escolha e quais critérios foram utilizadas na pesquisa.

Em nossa pesquisa de campo, realizada no segundo semestre de 2019, docentes entrevistadas falam sobre as relações entre saúde, trabalho e gênero. A particularidade da segunda metade da década de 2010 surge, entretanto, no debate. O aprofundamento da contrarreforma do Estado e seus impactos na educação superior pública em curso nas últimas décadas, com destaque para o subfinanciamento público, a privatização e a intensificação do trabalho docente se combinam com elementos da atual conjuntura. Se somam como determinantes das relações entre trabalho e saúde no cotidiano da universidade, o reacionarismo, o antiintelectualismo e o autoritarismo.

As docentes entrevistadas citaram as transformações no País a partir de 2016, com destaque para o aprofundamento do desmonte das políticas públicas, como determinantes das relações entre trabalho e saúde. Houve, por outro lado, aspectos contraditórios acerca da caracterização do governo atual e de como enfrentar o momento atual. A política para a educação superior do atual governo Bolsonaro foi objeto de crítica e de grande preocupação pela maior parte das docentes entrevistadas. No marco da consciência possível, entretanto, algumas ressaltaram os aspectos positivos do governo federal para a universidade pública. Elementos próprios das transformações nas universidades públicas nas décadas recentes, tais como o empreendedorismo e o produtivismo, somam-se aos argumentos vinculados à necessidade de uma certa resiliência. A necessidade da resistência e luta como forma de enfrentar os desafios colocados pela conjuntura econômica e política atual. E é sobre esse recorte da pesquisa que nos debruçamos no presente artigo.

\section{Breve trajetória da política de educação superior no Brasil: do período militar ao governo Bolsonaro}

Mesmo com o fim da ditadura militar para uma transição democrática, se mantém traços conservadores estruturais com a eleição de Fernando Collor de Mello, entre 1990-1992, após vinte anos de ditadura. Collor derrota Luís Inácio Lula da Silva nas eleições, este que na época era representante do Partido dos Trabalhadores e tinha histórico de lutas, junto aos movimentos populares.

No período de Fernando Henrique Cardoso (FHC), há continuidade com o período de políticas educacionais de "privatização, flexibilização e desresponsabilizacão implementadas pelo Estado, em consonância com as orientações emanadas dos organismos multilaterais" (BITTAR; BITTAR, 2012, p. 165).

No decorrer da década de 1990, com a implementação de políticas de ajuste neoliberal, são ampliados os espaços privados no que antes era lugar de políticas sociais públicas. A reforma educacional é decorrente da nova organização do trabalho e não se restringe ao Brasil, pois se dá no nível mundial. No final do século XX, o capitalismo vive mais uma crise estrutural, seguida de uma reforma no Estado que impõe um novo modelo para 
o ensino superior, afinado às pressões externas de organismos internacionais que inserem a educação pública, no âmbito de atividades econômicas. No Brasil, nos anos 1990, se aponta para uma tentativa de implantação do modelo gerencial para as universidades pautado na lógica empresarial e da competitividade (MANCEBO; MAUÉS; CHAVES, 2006). Vivenciamos hoje, o avanço do projeto neoliberal.

A educação superior manteve-se com absurda desigualdade de acesso e permanência de discentes. Com a posse de Lula, em 2003, é notório, apesar dos equívocos, que o governo Lula investiu na educação superior pública, em especial, no quesito acesso (e isso tem repercussões para o trabalho docente hoje, conforme apontado pela maioria das docentes nesta pesquisa) (BITTAR; BITTAR, 2012).

Em suma, a ditadura possui um projeto de nacional desenvolvimento de reforma da educação superior que aumentou as funções da universidade de forma desigual, vinculado a interesses econômicos da burguesia nacional e internacional, pautado na privatização e na repressão à resistência.

No Brasil, a partir da década de 1990, teve início sistemático, uma série de reformas implementadas pelo Estado, desde Fernando Collor de Mello que ressaltou a primazia do setor privado, em detrimento do público (MANCEBO; MAUÉS; CHAVES, 2006).

Já no governo FHC, há um aprofundamento do neoliberalismo com um intenso processo de sucateamento das instituições públicas e restrições de gastos em políticas sociais públicas, entre elas, a política de educação. A política de FHC (1997-2001) resultou no desmonte das universidades públicas em todo País, em decorrência da política de financiamento contingenciada que se caracteriza pela não contratação de professores e sem expansão significativa das universidades federais. A diminuição dos recursos no orçamento das universidades públicas reduziu a possibilidade de abertura de novos cursos, impossibilitou melhora na infraestrutura que efetivassem as atividades de ensino, pesquisa e extensão (SILVA, 2018).

Além da restrição orçamentária e problemas com a infraestrutura das universidades, foi um período de desvalorização salarial para os docentes em que os salários dos professores foram congelados por cinco anos, resultando em precarização do trabalho e adoecimento dos docentes universitários.

Esse cenário serviu de munição para legitimar o discurso da privatização dentro das universidades, ao argumentar que, por meio de cobranças de mensalidades, seria possível resolver os problemas das instituições. No governo FHC, tal como agora, universidades públicas sofreram fortes ataques, tendo inaugurado o processo de privatização das universidades (SILVA, 2018).

Assim, o trabalho docente é afetado por conta das novas configurações na esfera da Educação que, no Brasil, começam a se desenhar nas décadas de 1980 e 1990 conjugadas a uma série de mudanças do Estado, ao enfatizar uma suposta superioridade do setor privado em relação ao setor público (MANCEBO; MAUÉS; CHAVES, 2006).

Como marcos a Lei de Diretrizes e Bases da Educação Nacional (LDB) ${ }^{1}$, em 1996, regulamenta o ensino como mercadoria, ao legitimar a inserção do empresariado na educação superior (BRASIL, 1996). Nesse período surge, também, o financiamento estudantil para pagamento de cursos em instituições particulares, de modo a ampliar o ensino em instituições particulares, sem investir na educação pública. De acordo com essa nova proposta, advinda com a LDB-EN, o professor pesquisador que atua na pós-graduação precisa passar por uma série de exigências que tem impacto na avaliação trienal dos programas aos quais estão inseridos, além do imperativo de produzir e publicar determinado número de artigos em revistas classificadas pela agência.

Nos anos 2000, há continuidade e aprofundamento do projeto neoliberal com transformações orientadas pelo capital internacional. Nesse período, no Plano de Desenvolvimento da Educação (PDE) são apontadas cinco metas do governo federal: expansão das vagas; qualidade do ensino; inclusão social pela educação; ordenamento territorial ao levar a educação superior ao interior e fortalecimento do desenvolvimento econômico com recursos humanos e produção científica tecnológica (BRASIL, 2006). Sob o discurso da universalização, se amplia o setor privado também.

Com relação à expansão, o governo Lula constrói quatro programas: Programa Universidade para Todos (PROUNI); o Programa Expandir, o Sistema Universidade Aberta do Brasil (UAB) e o Programa de Reestruturação e Expansão das Universidades Federais (REUNI).

Nos governos petistas, entre as medidas indicadas, destacam-se: o Programa de Apoio à REUNI; PROUNI e o Fundo de Financiamento Estudantil (FIES).

Em 2004, o PROUNI expande o acesso à universidade, via parceria do Estado com faculdades privadas, por meio de bolsas de estudos, de modo a garantir o lucro dos empresários da educação (SILVA, 2018). 
Essa conjuntura possui alguns marcos, tais como o Programa de Apoio a REUNI, PROUNI e o FIES. Esses programas ampliaram as oportunidades de docentes universitários no ensino superior privado (SILVA, 2018).

É importante mencionar a compra de vagas na iniciativa privada, via PROUNI, sancionada em janeiro de 2005, que pactua o oferecimento de bolsas a pessoas de baixa renda, mediante isenções fiscais e, com isso, privilegia as instituições de ensino superior privadas, em detrimento das universidades públicas (MANCEBO; MAUÉS; CHAVES, 2006), abertura de mais de quarenta campi e criação de nove universidades federais, sem contrapartida de recursos econômicos, a abertura do ensino a distância, com destaque para a UAB, estratégias que ampliam o acesso, sem questionar a garantia da qualidade.

À luz do materialismo histórico dialético podemos compreender as contradições no âmbito das políticas públicas pelo Estado que toma partido pelo grande capital e que, a partir de 1990, é marcada pela retirada dos direitos sociais e na esfera da educação pela privatização do ensino superior público (SILVA, 2018).

Como produto desse processo, na Educação e, em especial, no ensino superior público, vivenciamos as experiências de uma reforma estrutural através da privatização ${ }^{2}$ que afetou, entre outros elementos, a organização do trabalho docente (MANCEBO; MAUÉS; CHAVES, 2006).

Ocorreram profundas alterações no trabalho dos docentes em universidades públicas, oriundas de imposições de novas formas de organização do trabalho docente, a partir da proposta de reforma educacional e que pode sugerir repercussão na saúde desses trabalhadores. No entanto, Souza et al. (2017) afirmam que não há estudos que analisem a real proporção do problema para saúde de docentes, em universidades públicas no Brasil.

Em decorrência da reforma educacional, o trabalho docente passou por novas configurações que puderam repercutir tanto na atividade do professor, quanto nas consequências para a saúde desses trabalhadores (SOUZA et al., 2017). Nesse sentido, Coutinho, Magro e Budde (2011, p. 159) argumentam que "a cobrança por produtividade, a introdução de tecnologias informacionais e a flexibilização dos horários de trabalho do professor são os principais fatores geradores de intensificação e ampliação do tempo de trabalho"; sendo assim, a elevada carga de trabalho traria exaustão física e mental com implicações para saúde dos professores. Os autores ressaltam ainda, queixas por parte dos docentes, sobre o elevado número de aulas e superlotação das salas quando vinculados à graduação e, nos programas de pós-graduação, a exigência de aumento de produção científica, como a publicação de artigos.

Gradella Júnior (2010) identificou em sua pesquisa as consequências para a saúde psicossomática e/ ou física, em docentes de universidades públicas, relacionadas à organização do trabalho, como geradoras de sofrimento psíquico e alienação. $\mathrm{O}$ autor assinala os distúrbios relacionados às condições de trabalho como hérnia de disco, coluna cervical, inflamação nas omoplatas e problemas de visão e outros de ordem psicossomática, como gastrite, úlcera nervosa, diabetes, fístula gastrointestinal, enfarto e labirintite e alguns que não mantêm relação direta com as relações de trabalho, como linfedema, tumor de mama e ovário (GRADELLA JÚNIOR, 2010).

Além disso, Gradella Júnior (2010, p. 142) aponta como "o sofrimento psíquico vai se construindo, juntamente com o processo de esvaziamento da atividade, interferindo não só na atividade propriamente dita, mas na relação do sujeito com sua própria vida". Este esvaziamento da atividade está, segundo o autor, ligado à lógica produtivista que afasta o docente das relações que não sejam a produção em si, adentrando a vida privada, sem espaço de tempo para as relações interpessoais, descanso ou atividades sindicais.

Em 2016, ocorre o impedimento da presidenta Dilma Rousseff, e com isso Michel Temer torna-se o presidente interino até o fim do mandato. Frente à crise econômica, com o desemprego e a queda nas condições de vida dos trabalhadores, alguns setores da direita entram num processo de crescimento, o que resulta na eleição de Jair Bolsonaro, que possui um discurso econômico ultraneoliberal. Cislaghi et al. (2019) discorrem sobre o acompanhamento do governo Bolsonaro no âmbito da política de educação e apontam para um estrangulamento dos recursos voltados às políticas sociais públicas, justificado pela opção por uma política ultraneoliberal ainda mais intensa que em qualquer governo anterior. A título de exemplo destaca-se a Emenda Constitucional 95/2016, que estabelece um teto de gastos primários por parte do governo a fim de garantir fundo público para juros e amortização da dívida pública. Em especial, no ensino superior com cortes de bolsas nos programas de pós-graduação, em especial na área de humanas, congelamento de bolsas de pesquisa e cortes de verbas. Para além do desfinanciamento, é presente no discurso do atual governo intensos ataques ideológicos contra a universidade pública, citada como espaços de balbúrdia. 


\section{Resultado e discussão}

Neste artigo, damos ênfase ao enfoque de uma categoria empírica encontrada na fala das docentes durante as entrevistas: a influência da conjuntura político-econômica, de diferentes governos, na educação superior pública.

Sobre a política educacional nos governos petistas é consenso, entre as entrevistadas, que houve uma ampliação nos governos petistas com programas como o REUNI. Embora tenha sido questionada a forma como essa expansão e interiorização foi realizada, já que o aumento no número de discentes não foi proporcional ao número de docentes. Dados relativos ao período entre 2007 e 2011 apontam aumento na expansão de vagas e cursos de graduação presenciais. Silva Júnior (2017) cita a ampliação de 2.327 cursos (76,8\% a mais) e 311.544 novas matrículas (50,7\% a mais).

A expansão de vagas e cursos acarreta maior número de discentes sem acompanhar abertura de concursos para contratação de docentes. Esse desajuste, com destaque para o REUNI e a UAB, afeta o trabalho docente e visa acelerar a dinâmica da produtividade, numa lógica de consumo com diminuição no tempo dos cursos, reduzindo também a constituição de um coletivo e ampliando o número de alunos, sem questionamento crítico da qualidade.

Para maior parte das entrevistadas, o REUNI do governo Lula é citado como uma oportunidade única de ampliação e interiorização da universidade pública. A entrevistada 1 diz que "boa foi a ampliação [...], eu acho que teve a oportunidade de ampliar mesmo o número de universidades e de interiorizar, eu acho que isso foi bom para as pessoas que tinham dificuldade de deslocamento". Ao mesmo tempo, a docente questiona a forma como foi feita tal ampliação ao dizer: "acho que o trabalho ficou mais precarizado", já que a demanda ficou maior por conta do maior número de ingressos. Apesar de questionar a "ampliação precarizada", a docente considera que foram feitas mudanças importantes quanto ao acesso dos discentes, abertura de cursos e na estrutura física.

Houve um dissenso dentro da universidade a respeito da adesão ao REUNI e a professora entrevistada 10 salienta: "acabamos acatando a participação" ao programa, já que havia uma contrapartida financeira importante para as universidades que aderissem; com a entrada do REUNI foram injetados recursos financeiros na Universidade, ainda que, na correlação de forças, alguns cursos fossem mais privilegiados que outros. Assim, houve embates quanto às instalações físicas para receber a demanda de alunos e cursos.

Contudo, os avanços dos governos petistas ao inserir pessoas mais pobres nas universidades estatais podem ter diminuído um pouco o abismo da desigualdade social quanto ao acesso ao curso superior.

Além da expansão e interiorização, as professoras 6 e 10 alertaram sobre a mudança no currículo que aparece como desdobramento desse processo. Na fala das duas entrevistadas aparecem conceitos como "interdisciplinaridade" ou "multidisciplinariedade"; "a universidade mais próxima da vida das pessoas", "a universidade transformada", lançando mão de estratégias como a extensão universitária, que aproxima docentes e discentes da comunidade. Isto é, o reforço do tripé ensino, pesquisa e extensão.

A docente 6 ressalta também que a universidade sofreu transformações positivas, assim como o conjunto da sociedade que resultou na inserção de mulheres em diferentes espaços, que ainda hoje é reduzido, mas que, no período citado, era ainda mais restrito, assim como o acesso, ainda mais elitizado, como a própria docente se refere.

$\mathrm{O}$ fato de ser mulher atuante na pesquisa, em cursos majoritariamente femininos, afeta a credibilidade do trabalho da docente, quando a professora menciona: "é um bando de mulher, nós somos pequenas, elas só incomodam...”. Não por acaso, a predominância feminina em espaços de menor prestígio, considerados com menor relevância social (KERGOAT, 2009). E a ascensão masculina de homens brancos, aos cargos e espaços de poder, era ainda maior do que é hoje.

Em termos de fomento à política de educação superior pública, a docente 11 relata que passou por diferentes mudanças de governo e compara o governo de Bolsonaro com o de FHC:

O Bolsonaro está sendo muito ruim e comparo com o FHC que era um período muito ruim, que a gente não tinha a compra de absolutamente nada, a gente tinha que comprar giz pra dar aula, apagador de quadro de giz, porque não tinha absolutamente nada, nem papel se duvidasse. 
O governo FHC, a partir de 1995, com seu ministro da educação, Paulo Renato de Souza, tinham um projeto de mudança para o ensino superior no Brasil, em sintonia com a direção dada às políticas públicas naquele governo, pautada pelas grandes privatizações, reforma do estado e da previdência e em outros âmbitos, que se justifica pela "desconfiança na esfera pública e aposta no setor privado" (FONSECA, 2018, p. 306).

A referida docente critica os ataques ideológicos que o atual governo faz contra a universidade ao dizer que: "o afronto é mais direto, [...] que a gente planta maconha, que aqui só anda gente pelada, e que a matéria de química ensina como fazer drogas sintéticas, então assim não dá pra levar a sério um governo nesse nível. Eu pelo menos não levo a sério". Faz distinção entre os governos anteriores com relação ao ataque ideológico sem precedentes (professora 11).

Segundo Leher (2019), o governo Bolsonaro teve como um dos principais temas a educação, mais especificamente $o$ ataque às universidades e instituições públicas. Trata-se de um governo ultraneoliberal, do qual fazem parte banqueiros e organizações financeiras, assim como o setor do agronegócio. Este governo também tem como aliados grupos fundamentalistas oriundos de igrejas pentecostais e neopentecostais. Esse grupo de extrema direita utiliza argumentos delirantes de que há um complô comunista internacional liderado pela China contra o ocidente e por isso tem como proposta acabar como o "marxismo cultural".

Leher (2019) faz uma análise preliminar sobre o programa Institutos e universidades inovadoras, também conhecido como Future-se, o qual traz como ponto central em sua ementa o empreendedorismo e a inovação, ao sugerir aos institutos e universidades federais, medidas inovadoras atreladas ao mercado (capitalista dependente) em um futuro idealizado como positivo. Logo, aquelas instituições que não aderirem estão fadadas ao fracasso.

O discurso utilizado pelo governo, através do Ministério da Educação (MEC), para se legitimar, traz como exemplo leituras equivocadas de experiência de universidade nos países desenvolvidos. Assim, com referências de países centrais, julgadas como exitosas (sem considerar que o Brasil se insere como país de capitalismo dependente. Este programa do governo federal prevê, entre outras coisas, que a universidade se mantenha com verbas próprias (LEHER, 2019).

Um ponto-chave dessa mudança de governo é o mito do professor-empreendedor que já cooptou alguns docentes; trata-se de uma estratégia de sobrevivência. É percebida pela fala das professoras, uma cisão entre docentes-pesquisadoras que entraram há pouco tempo na universidade e as que têm mais tempo de casa. Como observado na fala da jovem docente, inserida na UFF há cerca de três anos, ao dizer que "[...] as instituições de fomento, elas querem produção, [...] a gente que é jovem, que é pesquisador novo, que não tem ainda a carreira bem estabelecia e precisa correr atrás desses editais, precisa melhorar, precisa orientar alunos" (Entrevistada 3).

Ela fala também sobre seu perfil voltado para a pesquisa e enfatiza a distribuição de recursos a partir de editais. Ela relata: "as coisas que eu tenho disponíveis pra mim eu consegui por conta própria, por editais de pesquisa que eu submeti" (Entrevistada 3). Há um esforço individual que o docente precisa fazer para conseguir mais recursos e isso acompanha a trajetória de jovens pesquisadores/as desde a graduação.

Para a entrevistada 3, há uma pressão maior para os professores que se identificam mais com um "perfil de pesquisador". Segundo a entrevistada, "nesse perfil, estão as pessoas que estão orientando mestrado, doutorado, concorrendo a edital disso, tentando conseguir verba pra pesquisa, pro que for, esse é pra mim o que tem mais pressão, e com certeza afeta a estabilidade emocional". A docente ressalta que essa pressão parte da escolha de atuar na área da pesquisa e menciona que "é uma pressão que não vem necessariamente da instituição, não é uma coisa institucional é uma coisa que vem da sua decisão de onde você atuar, entendeu?".

Silva Júnior (2017, p. 57) elucida em sua pesquisa "a articulação entre a economia nesse momento do capitalismo e as mudanças institucionais" ao desvelar as transformações ocorridas na universidade estatal brasileira e nas universidades estadunidenses com argumentos de mercantilização da educação superior em ambos os países e no trabalho do professor pesquisador como um produto demandado, em função da nova economia, globalização ou do capitalismo acadêmico. Com isso, há mudanças na gestão, na legislação, nas políticas educacionais e institucionais e que têm reflexo no trabalho dos docentes (SILVA JÚNIOR, 2017).

Essa busca de recursos por conta própria pelo docente, citada na fala de docentes que construíram sua carreira na universidade, pode acirrar a competitividade entre seus pares, como fica explícito na fala da entrevistada 6, ao comentar que a competitividade "corrompe e corrói o caráter das pessoas, as pessoas se tornam indiferentes, as pessoas recusam a participação das outras em projetos". 
Entre as entrevistadas observa-se uma cisão: as mais jovens (menor tempo de universidade e de idade) e as mais velhas (com maior tempo de universidade e com idade mais avançada, que realizaram sua formação dentro da instituição) se identificam com perfis de docente diferentes: umas como pesquisadoras e outras como um perfil acadêmico, de sala de aula.

A entrevistada 6 se reconhece como alguém que assumiu atividades administrativas de suma importância para a Universidade Federal Fluminense (UFF), mas, contraditoriamente, os recursos de editais ficam com professores com relevância acadêmica, o que se resume em produção e sobre isso afirma que trabalhou com muita gente, "mas sem ser a primeira no desenvolvimento daquelas pesquisas, então eu não tenho isso, eu não tenho essa relevância acadêmica, por exemplo, então eu não tenho grana. Eu não tenho dinheiro" (entrevistada 6).

Para a docente, a competição pode esgarçar as relações entre pares e ser fonte de adoecimento; sobre isso ela declara que "isso gera uma competição e uma concorrência... isso tudo que eu tô falando pra você, isso tudo dentro da Universidade se transforma em competição, elas quase que transformam trincheiras pra brigar por suas ideias, pelos seus projetos, sabe?". A entrevistada ainda complementa que a forma como as pessoas lidam pela disputa de espaços de poder e recursos afeta as relações de trabalho e afirma: "sabe quando você vê que você tá trabalhando com o inimigo? Era mais ou menos isso, e eu falei 'agora eu vou ter que abrir uma trincheira e ficar esperando a hora que o inimigo vai vir me bombardear, ou vocês vão ser colegas de trabalho?" (Entrevistada 6).

Para Sguissardi e Silva Júnior (2018), o produtivismo acadêmico é marcante na universidade, em especial na pós-graduação. $\mathrm{O}$ atual estágio de acumulação capitalista e a reforma do Estado que prioriza o privado em detrimento do público busca transformar a universidade em uma empresa de serviços que forma profissionais guiados pela produtividade do mercado e que exigem características típicas de organizações privadas, como o individualismo e a competitividade.

Em seu estudo, os autores afirmam que a concorrência ou competição nos Institutos federais pode ser exemplificado por um simples dado que é a bolsa de produtividade do Conselho Nacional de Desenvolvimento Científico e Tecnológico (CNPq), no qual apenas 10\% dos docentes-pesquisadores, em cada área do conhecimento, se beneficiam (CONSELHO NACIONAL DE DESENVOLVIMENTO CIENTÍFICO E TECNOLÓGICO, 2009 apud SGUISSARDI; SILVA JÚNIOR, 2018). Isto é, há uma acirrada disputa de recursos que está para além do valor monetário (baixo), mas que tem relação maior com a escala de prestígio e poder que o docente pode ocupar no mundo acadêmico e científico.

Nos países periféricos, de capitalismo dependente, é importante entender o papel da educação, em especial da universidade, visto que a dependência de produção do conhecimento e avanço técnico científico são essenciais para manter a subordinação (SILVA JÚNIOR; LUCENA, 2014). Para Fonseca (2018, p. 301), "nos últimos 20 anos, a universidade pública passa por momentos importantes 'em sua retração e em sua expansão, na sua elitização e democratização"”.

Entre os países centrais e periféricos há uma desigualdade científica e tecnológica (MINAYO, 2010). Para entender como se insere o Brasil e o lugar que se encontra a universidade pública brasileira é necessário perceber como se dão as relações entre países centrais e periféricos, ou seja, a inserção do Brasil no mundo capitalista. Compreender que lugar o país ocupa no contexto geopolítico e o que fundamenta a relação de dependência é quando a mais valia de um país periférico é absorvido por algum país central (SILVA JÚNIOR; MANCEBO, 2016).

A respeito dos efeitos para o corpo docente, a entrevistada 11 relata: "a gente vive em um meio que se a gente não acredita que pode melhorar alguma coisa... vai viver do quê? Eu continuo tentando acreditar que isso vai melhorar, mas confesso que cada dia que passa está cada vez mais difícil".

A professora entrevistada 9, teve seu percurso acadêmico recentemente construído dentro da universidade pública e, nesse período de formação na carreira docente, cita sobre as diferenças entre o atual governo Temer Bolsonaro e o anterior governo petista, no que diz respeito a oportunidades de bolsas de pesquisa, por exemplo, ao dizer que "oportunidades para os alunos diminuiu bastante, principalmente bolsas de iniciação (científica), bolsas de mestrado e doutorado". Outra docente, com trajetória similar a anterior percebe aspectos positivos e negativos no atual governo "[a organização] é uma coisa importante que foi imposta agora e que vai ajudar a Universidade ou pelo menos a unidade aqui a organizar melhor para caminhar de forma mais objetiva e não ficar gastando dinheiro à toa, e, também, tem essa questão da organização dos gastos" (entrevistada 12). 
É consenso entre as docentes entrevistadas, que há mudanças significativas com as trocas de governo. Apesar dos poucos anos na unidade de ensino, a entrevistada 2 afirma que, no momento, o que está em jogo é o sucateamento do serviço público com a falta de investimento nas universidades, com cortes no financiamento pelo governo federal. Ela relata que "governos anteriores, não eram perfeitos também, mas nunca se houve um ataque tão específico de cortes nas Universidades, para o ensino público, então de fato a gente tem vivido tempos mais sombrios em relação aos financiamentos".

As mudanças de governo também podem acarretar precarização material e nas condições de trabalho, conforme afirma a entrevistada 4 ao dizer que no governo anterior viu "a Universidade em plena ascensão, a gente tinha mais recurso financeiro dentro da Universidade, dentro da faculdade a gente podia ir para um congresso, a gente tinha a nossa passagem, a nossa estadia custeada e hoje isso já não acontece mais [...]" (Entrevistada 4).

Essas e outras mudanças afetam a saúde das trabalhadoras. A professora 5 enfatiza o desestímulo em trabalhar na atual conjuntura com possíveis cortes na educação superior pública, conforme já dito, mas também o ataque ao funcionalismo público no âmbito da educação superior com propostas inéditas de cortes de salários, redução de carga horária e constante questionamento sobre a estabilidade, tida como privilégio. Ela diz que "É o 'FUTURE-SE' e tem um outro que o Paulo Guedes lançou [...] não tem investimento para a educação, saúde, vai cancelar as progressões funcionais, vai reduzir carga horária e diminuir salário, então, assim, qual o estímulo que você tem para fazer um doutorado?" (Entrevistada 5).

Os cortes da educação superior não são novidade para as docentes, já foi apresentado por governos anteriores, mas o negacionismo científico é um aspecto ideológico importante que o diferencia dos anteriores. É um ataque ao que a universidade significa, tendo em vista seu desmonte. O negacionismo avançou tendo como pautas o obscurantismo e anticientificidade com intuito de desprezar as evidências, desconsiderando a ciência e o conhecimento (SENA JÚNIOR, 2019).

\section{Considerações finais}

As décadas dos anos 1970 e 1980 foram marcadas pela reestruturação produtiva e reajustamento político e social e nesse contexto surge o modelo de acumulação flexível (do mercado, das relações de trabalho, do processo de trabalho, dos produtos e dos padrões de consumo) em oposição ao modelo fordista de caráter rígido que se estabeleceu anteriormente. Essas mudanças associadas ao avanço tecnológico, que tem como produto mutações na organização do trabalho, e a crise fiscal colocam em xeque o welfare state, assim como o modelo fordista de acumulação.

Essas transformações, ocorridas no âmbito do trabalho, têm importante repercussão para a dinâmica da universidade e os trabalhadores da educação superior pública. No Brasil, essas mudanças se intensificaram durante a década de 1990, em que houve um avanço do modelo neoliberal, considerando a contrarreforma do Estado e seus efeitos para a educação pública.

O discurso das professoras expressa o avanço do projeto neoliberal no Brasil que atinge seu ápice com a eleição do atual governo de caráter ultraneoliberal que tem cometido ataques contra a educação superior pública. A ofensiva vai para além do contingenciamento dos gastos, o governo apresenta duros ataques ideológicos à universidade com controle do conteúdo sob a justificativa de que há doutrinação nas universidades públicas.

\section{Referências}

BITTAR, M.; BITTAR, M. História da Educação no Brasil: a escola pública no processo de democratização da sociedade. Acta Scientiarum Education, Maringá, v. 34, n. 2, p. 157-168, ago. 2012.

BRASIL. Lei no 9.394, de 20 de dezembro de 1996. Estabelece as diretrizes e bases da educação nacional. Brasília, 20 dez. 1996. Disponível em: http://www.planalto.gov.br/ccivil_03/leis/19394.htm. Acesso em: 21 dez. 2020.

BRASIL. Ministério da Educação. Como Elaborar o Plano de Desenvolvimento da Escola. Brasília, DF: Fundo Nacional de Desenvolvimento da Educação, 2006. Disponível em: ftp://ftp.fnde.gov.br/web/fundescola/publicacoes_manuais_tecnicos/pde_escola. pdf. Acesso em: 21 dez. 2020. 
CISLAGHI, J.F. et al. Não é um uma crise, é um projeto: A política de educação do governo Bolsonaro. In: CONGRESSO BRASILEIRO DE ASSISTENTES SOCIAIS, 16., 2019, Brasília. Anais [...]. Brasília: 16CBAS, 2019.

CONSELHO NACIONAL DE DESENVOLVIMENTO CIENTÍFICO E TECNOLÓGICO (CNPq). Produtividade em Desenvolvimento Tecnológico e Extensão Inovadora - DT. Normas. Brasília: CNPq, 2009. Disponível em: www.cnpq.br/normas/rn_06_016_anexo2. htm. Acesso em: 21 dez. 2020.

COUTINHO, M. C.; MAGRO, M. L. P. D.; BUDDE, C. Entre o prazer e o sofrimento: um estudo sobre os sentidos do trabalho para professores universitários. Psicologia: Teoria e Prática, São Paulo, v. 13, n. 2, p. 154-167, ago. 2011.

FONSECA, R. M. Democracia e acesso à universidade no Brasil: um balanço da história recente (1995-2017). Educar em Revista, Curitiba, v. 34, n. 71, p. 299-307, set./out. 2018. Disponível em: https://www.scielo.br/pdf/er/v34n71/0104-4060-er-34-71-299.pdf. Acesso em: 19 dez. 2020.

GRADELLA JÚNIOR, O. Sofrimento psíquico e trabalho intelectual. Cadernos de Psicologia Social do Trabalho, São Paulo, v. 13 , n. 1, p. 133-148, jan. 2010.

KERGOAT, D. Divisão Sexual do trabalho e relações sociais de sexo. In: HIRATA, H. et al. (org.). Dicionário crítico do feminismo. São Paulo: Unesp, 2009. p. 67-75.

LEHER, R. Autoritarismo contra a universidade: o desafio de popularizar a defesa da educação pública. São Paulo: Fundação Rosa Luxemburgo, Expressão Popular, 2019.

MANCEBO, D.; MAUÉS, O.; CHAVES, V. L. J. C. Crise e reforma do Estado e da Universidade Brasileira: implicações para o trabalho docente. Educar em Revista, Curitiba, n. 28, p. 37-53, 2006.

MINAYO, M. C. O desafio do conhecimento: pesquisa qualitativa em saúde. São Paulo: Hucitec, 2010.

SENA JÚNIOR, C. Z. Obscurantismo e anticientificismo no brasil bolsonarista: anotações sobre a investida protofascista contra a inteligência e a ciência no brasil. Cadernos do GPOSSHE On-Line, v. 3, n. 1, p. 21-49, out. 2019.

SGUISSARDI, V; SILVA JÚNIOR, J. R. O trabalho intensificado nas federais: pós-graduação e produtivismo acadêmico. Uberlândia: Navegando Publicações, 2018.

SILVA JÚNIOR, J. R. The new Brazilian university: a busca por resultados comercializáveis: para quem? São Paulo: Projeto Editorial Práxis, 2017.

SILVA JÚNIOR, J. R.; FARGONI, E. H. E. Bolsonarismo: a necropolítica brasileira como pacto entre fascistas e neoliberais. Dossiê: "Consequências do bolsonarismo sobre os direitos humanos, a educação superior e a produção científica no Brasil". Revista Eletrônica de Educação, v. 14, e4533133, p. 1-26, jan./dez. 2020. Disponível em: http://www.reveduc.ufscar.br/index.php/reveduc/article/ download/4533/1055. Acesso em: 15 dez. 2020.

SILVA JÚNIOR, J. R.; LUCENA, C. A. O tempo, o trabalho e o ser social professor-pesquisador. Educação e Filosofia, v. 28, p. 445-472, 2014.

SILVA JÚNIOR, J. R.; MANCEBO, D. Considerações sobre a universidade (nos Estados Unidos e Brasil) e a financeirização da economia mundial. Germinal: Marxismo e Educação em Debate, Salvador, v. 8, n. 1, p. 91-100, jul. 2016.

SILVA, A. A. R. Contrarreforma da educação superior brasileira: a expansão e a privatização do ensino. In: SEMINÁRIO CETROS, 6., 2018, Ceará. Anais [...]. Ceará: UECE, 2018. p. 1-14.

SOUZA, K. R. A nova organização do trabalho na universidade pública: consequências coletivas da precarização na saúde dos docentes. Ciênc. Saúde Coletiva, Rio de Janeiro, v. 22, n. 11, nov. 2017. DOI https://doi.org/10.1590/1413-812320172211.01192016. Disponível em: https://www.scielo.br/scielo.php?script=sci_arttext\&pid=S1413-81232017021103667. Acesso em: 20 dez. 2020.

\section{Notas}

1 Em 1996 a Lei de Diretrizes e Bases da Educação Nacional (LDN-EN) impôs a contratação de 1/3 de doutores ou mestres em regime de dedicação integral para se dedicar à pesquisa, o que fomentou a pós-graduação no Brasil. A Capes, agência de avaliação da pós-graduação, criada na década de 1950, potencializa seu poder regulador (SGUISSARDI; SILVA JÚNIOR, 2018).

2 A privatização compreende "não só seu aspecto visível, qual seja, a privatização ou o (des)investimento do Estado na educação superior pública, como também a delegação de responsabilidades públicas para entidades privadas; a reconfiguração quanto à oferta do ensino superior com o estímulo a uma série de ações delegatórias às iniciativas empresariais destinadas a substituir ou a complementar as responsabilidades que os governos recusam, ou assumem apenas parcialmente e, no caso das universidades, a mercantilização do conhecimento, dentre outros aspectos" (MANCEBO; MAUÉS; CHAVES, 2006, p. 44). 


\section{Thiele Duarte Reis}

Thieleduarte1@gmail.com

Mestra em Saúde Coletiva pela Universidade Federal Fluminense (UFF)

\section{Claudia March}

claudiamarch@id.uff.br

Doutora em Serviço Social pela Universidade Federal do Rio de Janeiro (UFRJ)

Docente da Universidade Federal Fluminense (UFF)

\section{ISC-UFF}

Rua Marquês do Paraná, 303 - $4^{\circ}$ andar

Niterói - Rio de Janeiro - Brasil

CEP: 24030-210

\section{Agradecimentos}

Agradecemos as docentes que participaram desta pesquisa.

Agência financiadora

Não se aplica.

Contribuições das autoras

Artigo fruto de pesquisa realizada pela mestranda Thiele Duarte

Reis, sob co-orientação da $\operatorname{Prof}^{\mathrm{a}} \mathrm{Dr}^{\mathrm{a}}$ Claudia March.

Aprovação por Comitê de Ética e consentimento para

participação
Aprovado pelo comitê de Ética em Pesquisa da Faculdade de Medicina da Universidade Federal Fluminense e aprovada CAAE 14341919.8.0000.5243 parecer de $n^{\circ} 3.383 .563$. Todos os participantes assinaram e receberam cópia do Termo de Consentimento Livre e Esclarecido.

\section{Consentimento para publicação}

Consentimento das autoras.

Conflito de interesses

Não há conflito de interesses. 